\title{
Association between dental health and acute myocardial infarction
}

\author{
Kimmo J Mattila, Markku S Nieminen, Ville V Valtonen, Vesa P Rasi, Y Antero Kesäniemi, \\ Satu L Syrjälä, Peter S Jungell, Martti Isoluoma, Katariina Hietaniemi, Matti J Jokinen, \\ Jussi K Huttunen
}

\begin{abstract}
Known risk factors for coronary heart disease do not explain all of the clinical and epidemiological features of the disease. To examine the role of chronic bacterial infections as risk factors for the disease the association between poor dental health and acute myocardial infarction was investigated in two separate case-control studies of a total of $\mathbf{1 0 0}$ patients with acute myocardial infarction and 102 controls selected from the community at random. Dental health was graded by using two indexes, one of which was assessed blind. Based on these indexes dental health was significantly worse in patients with acute myocardial infarction than in controls. The association remained valid after adjustment for age, social class, smoking, serum lipid concentrations, and the presence of diabetes. Further prospective studies are required in different populations to confirm the association and to elucidate its nature.
\end{abstract}

\section{Introduction}

The development of coronary heart disease is attributed to several risk factors such as high serum cholesterol concentration, low serum high density lipoprotein cholesterol concentration, smoking, hypertension, and diabetes. ${ }^{12}$ These risk factors, however, seem to explain only half to three quarters of the variation in the incidence of cases of coronary heart disease in most industrialised societies. ${ }^{12}$ Thus important risk factors seem not yet to have been identified.

There is evidence that acute viral infections and influenza-like illness may precipitate myocardial infarction in susceptible people. ${ }^{3}$ Special attention has been given to infections with coxsackieviruses, which affect the myocardium and coronary arteries. ${ }^{+6}$ Bacterial infections have also been incriminated in the aetiology of both coronary heart disease and stroke. ${ }^{78}$ Based on a clinical impression that chronic dental infections are common among patients with acute myocardial infarction we carried out two separate casecontrol studies in which we investigated the dental health of patients with acute myocardial infarction and controls selected from the community at random.

\section{Subjects and methods}

Two series of patients with acute myocardial infarction and controls were investigated. The patients in the first series (series 1 ) comprised 40 consecutive men admitted to Helsinki University Central Hospital because of acute myocardial infarction. The criteria for including the men in the study were that they were aged 50 or less, were resident in Helsinki or its immediate neighbourhood, had developed their symptoms within 36 hours before admission, and had acute myocardial infarction as verified by typical changes in their electrocardiograms and raised serum creatinine phosphokinase isoenzyme MB activity. The controls were a computer based random sample of 41 men from the official records of inhabitants of Helsinki. They were in the same age group as the patients and lived in the same area. One of them was taking a $\beta$ blocker for hypertension. The rest were not taking any drugs and did not have any chronic diseases. Sixty five per cent of those invited agreed to participate.

The patients in the second series (series 2) comprised 60 consecutive people with acute myocardial infarction. The criteria for inclusion were that they were men aged 60 or less or women aged 65 or less, their symptoms had started within 36 hours before the admission, and they lived in Helsinki or its immediate neighbourhood. The controls were 61 subjects individually matched for sex and age with the patients. They were collected from the official records of inhabitants of Helsinki. Eighty six per cent of those invited agreed to participate. None of them had previously had myocardial infarction. Two had symptoms of angina pectoris, 12 were taking antihypertensive drugs, eight had received antihypertensive treatment previously, one had non-insulin dependent diabetes, and one had insulin dependent diabetes.

In both series each matched control was invited to be examined as soon as the patient had been admitted to the hospital. If the control refused to participate or did not answer (non-respondent) another control was selected randomly from the computer list. In both series one control who did not respond initially contacted the investigators later and was included in the series. Thus the number of controls exceeded the number of patients by one in both series.

Blood samples for measurements of serum total cholesterol, triglyceride, and high density lipoprotein cholesterol concentrations were taken on admission and four weeks later from all subjects except three, two of whom died before the second visit (one in both series) and one of whom dropped out of the study (series 1). The lipid values obtained during the second visit were used in the analyses.

All patients and controls were examined by one doctor (KJM). Special attention was paid to history of infections, smoking habit, and hypertension. The social class of each subject was defined on the basis of his or her occupation. This information was obtained either at the interview (for patients and respondent controls) or from the official records of inhabitants (for non-respondent controls). Informed consent was obtained from all participants before examination. The study protocol was approved by the ethical committee of Meilahti Hospital.

Dental examination-Dental health was assessed by two methods, both measuring the severity of infection of the teeth and the periodontium. A systematic clinical and radiological examination was carried out during the hospital stay or shortly after discharge. For practical reasons this examination could not be done 
without the dentist knowing whether the subject was a patient or control. Each person was given scores according to the severity of the dental disease (table 1). The arithmetic sum of the scores formed the "total dental index." The index ranged from zero to 10 , increasing with the severity of the disease. After the initial dental studies pantomographs were re-examined blind. The sum of the number of periapical lesions, lesions caused by tertiary caries, vertical bone pockets, radiolucent areas at the furcation, and lesions caused by pericoronitis formed the "pantomography index."

Laboratory analyses - Serum total cholesterol concentrations were determined enzymatically. ${ }^{9}$ High density lipoprotein was isolated from plasma by ultracentrifugation $^{10}$ and the high density lipoprotein cholesterol concentration determined. Serum C peptide concentration was determined by radioimmunoassay. "

Statistical methods-Sample proportions were

TABLE I-Scheme for calculating total dental index, which was used to evaluate dental health

\begin{tabular}{|c|c|}
\hline Type of disease & Score \\
\hline \multicolumn{2}{|l|}{ Caries: } \\
\hline No carious lesions & 0 \\
\hline 1-3 Carious lesions & 1 \\
\hline 4-7 Carious lesions or no teeth in maxilla or mandibula & 2 \\
\hline$\geqslant 8$ Carious lesions or relics radix or no teeth & 3 \\
\hline \multicolumn{2}{|l|}{ Periodontitis: } \\
\hline None & 0 \\
\hline Gingival pocket $4-5 \mathrm{~mm}$ deep & 1 \\
\hline Gingival pocket $\geqslant 6 \mathrm{~mm}$ deep & 2 \\
\hline Macroscopic pus in gingival pocket & 3 \\
\hline \multicolumn{2}{|l|}{ Periapical lesions: } \\
\hline None & 0 \\
\hline 1 Or vertical bone pocket, or both & 1 \\
\hline 2 & 2 \\
\hline$\geqslant 3$ & 3 \\
\hline \multicolumn{2}{|l|}{ Pericoronitis: } \\
\hline Absent & 0 \\
\hline Present & 1 \\
\hline
\end{tabular}

TABLE II-Demographic characteristics and conventional risk factors in two series of patients with myocardial infarction and their matched controls

\begin{tabular}{|c|c|c|c|c|}
\hline \multirow[b]{2}{*}{ Characteristic } & \multicolumn{2}{|c|}{ Series 1} & \multicolumn{2}{|c|}{ Series 2} \\
\hline & $\begin{array}{l}\text { Patients } \\
(n=40)\end{array}$ & $\begin{array}{l}\text { Controls } \\
(n=41)\end{array}$ & $\begin{array}{l}\text { Patients } \\
(n=60)\end{array}$ & $\begin{array}{c}\text { Controls } \\
(n=61)\end{array}$ \\
\hline \multicolumn{5}{|l|}{ Sex: } \\
\hline Male & 40 & 41 & 44 & 44 \\
\hline Female & & & 16 & 17 \\
\hline Mean $(\mathrm{SD})$ age (years) & $44(5)^{\star \star}$ & $39(6)$ & $52(8)$ & $52(8)$ \\
\hline Mean (SD) serum cholesterol $(\mathrm{mmol} / \mathrm{l})$ & $6 \cdot 4(1 \cdot 3)$ & $5 \cdot 9(1 \cdot 3)$ & $6 \cdot 0(1 \cdot 2)^{\star \star}$ & $6.7(1.5)$ \\
\hline \multicolumn{5}{|l|}{ Mean (SD) high density lipoprotein } \\
\hline cholesterol $(\mathrm{mmol} / \mathrm{l})$ & $1 \cdot 0(0 \cdot 3)^{\star \star \star}$ & $1 \cdot 4(0.4)$ & $1 \cdot 0(0 \cdot 4)^{\star \star \star}$ & $1.3(0.5)$ \\
\hline Mean $(\mathrm{SD})$ serum triglyceride $(\mathrm{mmol} / \mathrm{l})$ & $2 \cdot 4(1 \cdot 3)^{\star \star \star}$ & $1.4(0.8)$ & $2 \cdot 0(1 \cdot 9)^{\star \star}$ & $1.5(1.3)$ \\
\hline Mcan (SD) C peptide $(\mu \mathrm{g} / \mathrm{l})$ & $2 \cdot 5(2 \cdot 4)^{\star \star}$ & $1 \cdot 3(0 \cdot 8)$ & $3 \cdot 2(2 \cdot 0)^{\star \star}$ & $2 \cdot 3(1 \cdot 6)$ \\
\hline \multicolumn{5}{|l|}{ Smoking habit: } \\
\hline No $(\%)$ of current smokers & $30(75)^{\star \star}$ & $19(46)$ & $35(58)^{\star \star}$ & $20(33)$ \\
\hline No $(\%)$ of former smokers & $8(20)$ & $11(27)$ & $14(23)$ & $12(20)$ \\
\hline No $(\%)$ with hypertension $\dagger$ & $10(25)^{\star \star}$ & $1(2)$ & $22(37)$ & $20(33)$ \\
\hline No $(\%)$ with diabetes $\ddagger$ & $1(3)$ & 0 & $5(8)$ & $2(3)$ \\
\hline \multicolumn{5}{|l|}{ No $(\%)$ of social class $\S:$} \\
\hline I & $13(32)$ & $19(46)$ & $13(22)$ & $16(26)$ \\
\hline II & $11(28)$ & $9(22)$ & $13(22)$ & $18(30)$ \\
\hline III & $14(35)$ & $13(32)$ & $33(55)$ & $25(41)$ \\
\hline IV & $2(5)$ & 0 & $1(1)$ & $2(3)$ \\
\hline
\end{tabular}

Significance of difference between controls and patients for each series separately: ${ }^{\star \star} p<0.01 ;{ }^{\star \star \star} p<0.001$

† Subjects taking or who had previously taken antihypertensive drugs.

$\ddagger$ Subjects with manifest diabetes (both juvenile and maturity onset).

(Social class I=salaried employees, higher level; II = salaried employees, lower level; III=specialised blue collar workers; IV = unspecialised blue collar workers.

TABLE III - Dental health in two series of patients with myocardial infarction and their matched controls as indicated by total dental index, pantomography index, and no teeth

\begin{tabular}{|c|c|c|c|c|}
\hline & \multicolumn{2}{|c|}{ Series 1} & \multicolumn{2}{|c|}{ Series 2} \\
\hline & Patients & Controls & Patients & Controls \\
\hline Median total dental index $†$ & $4(2,5 \cdot 5)^{\star \star \star}$ & $2(1,3)$ & $6(4,7)^{\star \star}$ & $4(2,5)$ \\
\hline Median pantomography index $\uparrow$ & $2(1,4 \cdot 5)^{\star \star \star}$ & $0(0,1)$ & $6(4,9)^{\star \star}$ & $3(1,6)$ \\
\hline No (\%) with artificial teeth in both jaws & $4(10) 5$ & & $17(28)^{\star \star}$ & $6(10)$ \\
\hline
\end{tabular}

†The 25 th and 75 th centiles of the distribution are given in parentheses.

Significance of difference between controls and patients for each series separately: ${ }^{\star \star} p<0.01 ; \star \star \star p<0.001$ $\oint p=0.055$.
TABLE IV-Stepwise logistic regression with conventional risk factors and total dental index as independent variables. Subjects from two series were included in the analysis $(n=202)$

\begin{tabular}{lrrrr}
\hline $\begin{array}{l}\text { Independent } \\
\text { variable }\end{array}$ & Coefficient & $\begin{array}{c}\text { Standard } \\
\text { error }\end{array}$ & $\begin{array}{c}\text { Coefficient/ } \\
\text { standard } \\
\text { error }\end{array}$ & p Value \\
\hline High density lipoprotein & & & & \\
$\quad$ cholesterol & -3.41 & 0.65 & -5.24 & $<0.001$ \\
Smoking & 1.33 & 0.43 & 3.07 & 0.004 \\
Total dental index $\dagger$ & 0.23 & 0.09 & 2.55 & 0.004 \\
Hypertension $\neq$ & 0.78 & 0.42 & 1.85 & 0.06 \\
Age & & & & NS \\
Triglycerides & & & & NS \\
Social class & & & & NS \\
Diabetes & & & & NS \\
Total cholesterol & & & & NS \\
C peptide & & & &
\end{tabular}

*Current and former smokers.

tCoefficient for pantomography index was 0.12 (standard error 0.04 , $\mathrm{p}<0.002$ ) when tested in the model instead of total dental index.

$\ddagger$ Subjects taking or who had previously taken antihypertensive drugs.

compared by $\chi^{2}$ test (with Yates's correction) and Fisher's exact method. Student's $t$ test was used to compare means of quantitative variables. Logarithmic transformation was performed when necessary to obtain a normal distribution. Welch's method was used when the variances between groups differed significantly. For comparison of the dental indexes the non-parametric Mann-Whitney test was used. Interrelations between the risk factors were assessed with stepwise logistic regression analysis. ${ }^{12}$ Because the two dental indexes used to assess dental state were strongly correlated they were included separately in the analysis. Presence of diabetes and the serum $\mathrm{C}$ peptide concentration were treated similarly. Correlations between the dental indexes and between the total dental index and social class were expressed by Spearman's rank correlation.

\section{Results}

Table II shows the demographic characteristics and values of conventional risk factors of the study groups. Smoking was more common among these with acute myocardial infarction, and they had lower concentrations of high density lipoprotein cholesterol and higher serum concentrations of triglycerides and $\mathrm{C}$ peptide than the controls in both series. Hypertension was more common among the patients than the controls in series.' The differences in the prevalence of clinical diabetes and in the distribution of social classes between patients and controls were not significant. Serum total cholesterol concentration was not associated with myocardial infarction. In fact, the mean cholesterol concentration in series ${ }^{2}$ was higher in the controls than the patients.

As expected the total dental index and the pantomography index were highly correlated $(r=0.69$, $\mathrm{p}<0.001$ ), suggesting that the non-blind assessment of the total dental index was not biased. The two indexes were significantly higher (reflecting worse dental health) among patients than controls in both series (table III). Table IV shows the results of the stepwise logistic regression analysis, done to determine whether the association between coronary heart disease and poor dental health was independent of the other risk factors of coronary heart disease measured. Both dental indexes were tested with age; concentrations of total cholesterol, high density lipoprotein cholesterol, triglycerides, and C peptide; hypertension; presence of diabetes; and smoking habit. Inclusion of social class in the analysis only slightly influenced the regression coefficients of the dental indexes. The results were similar when the two series were analysed separately and when the data were pooled.

The total dental index correlated significantly with 
social class $(r=0.25 ; p<0.001)$, the subjects in the lower classes having worse dental health. To exclude the possibility that the difference observed in dental indexes between patients and controls was due to selection bias associated with social class we examined the social class distribution among patients, respondent controls, and non-respondent controls. The nonrespondents more commonly belonged to higher social classes $(p<0.05)$, whereas no differences were observed between patients and respondent controls (table II). Thus social class, which was probably the most important potential confounding factor, did not seem to influence our results.

\section{Discussion}

In two separate case-control series patients with acute myocardial infarction had worse dental health than controls matched for age and sex. Several possible explanations for this should be considered. Firstly, dental caries and ischaemic heart disease share several common aetiological factors - for example, low socioeconomic state, ${ }^{1314}$ smoking, diabetes, and resistance to insulin..$^{215-17}$ Secondly, subjects who take care of their dentition may also be concerned about other aspects of their health, including a lifestyle conducive to coronary heart disease. The relation between dental health and acute myocardial infarction, however, remained significant even after adjustment for age, social class, hypertension, serum lipid and lipoprotein concentrations, smoking, presence of diabetes, and serum $C$ peptide concentration (which reflects resistance to insulin).

A link between dental caries and ischaemic heart disease could also derive from diet. Two dietary constitutents, sucrose and fluoride, deserve attention. High consumption of sucrose is considered to be an important factor in the aetiology of caries, ${ }^{18}$ and sucrose has also been incriminated in the development of atherosclerosis. ${ }^{19}$ Data from recent epidemiological studies, however, do not support the hypothesis that high consumption of sucrose is related to the development of ischaemic heart disease. ${ }^{20}$ The role of fluoride as a protective agent against dental caries is firmly established." Studies with animals have suggested that supplements of fluoride may also prevent aortic calcification induced by deficiency of magnesium. ${ }^{.2}$ Epidemiological data on the role of deficiency of fluoride in the development of atherosclerosis are, however, conflicting. Though some studies have suggested an inverse relation between the prevalence of ischaemic heart disease and the fluoride content of drinking water, the bulk of the evidence does not support such a relation. ${ }^{23}$ Thus low intake of fluoride probably would not explain the connection between poor dental health and coronary disease found in this study.

The mechanism by which dental infections could influence the development of myocardial infarction remains unknown. Occlusive thrombus attached to atherosclerotic plaque is the most common cause of acute myocardial infarction. Bacterial components affect endothelial integrity, ${ }^{24} 25$ metabolism of plasma lipoprotein, ${ }^{26}$ blood coagulation,,$^{27}{ }^{28}$ and the function of platelets and their synthesis of prostaglandin, ${ }^{29}{ }^{30}$ all of which are factors that influence the progression of atherosclerosis and the processes triggering myocardial infarction and sudden death in subjects with coronary disease. ${ }^{3132}$ Many of these changes are mediated by the endotoxin associated with certain Gram negative bacteria, but other mechanisms must also play a part. On the other hand, little is known about the long term effects of chronic low grade bacterial infections, such as dental caries or periodontitis, on atherosclerosis and its complications. Gram negative bacteria containing endotoxin are also important factors in the course of periodontal infections. ${ }^{33}$ Thus the possibility that bacterial endotoxin or similar factors may be related to the association between myocardial infarction and dental health observed in the present study cannot be excluded.

Our observations indicate that dental caries or periodontal disease, or both, is more common among patients with acute myocardial infarction than among controls matched for age and sex. More prospective studies in various populations are, however, needed to confirm the association and to elucidate its nature.

This study was supported by the Academy of Finland and the Finnish Foundation for Cardiovascular Research and wa carried out under YAK's contract with the Finnish Life Insurance Companies.

1 Stamler J. Research related to risk factors. Circulation 1979;60:1575-87

2 Pooling Project Research Group. Relationship of blood pressure, serum cholesterol, smoking habit, relative weight and ECG abnormalities to incidence of major coronary events: final report of the pooling project. fChronic Dis 1978:31:201-306.

3 Spodick DH. Inflammation and the onset of mrocardial infarction. Ann Inter Med 1985;102:699-702.

4 Nikoskelainen J, Kalliomäk JL. Lapinleimu K, Stenvik $M$, Halonen PE. Coxsackie B virus antibodies in myocardial infarction. Acta Med Scand $1983 ; 214: 24-32$.

5 Nicholls AC, Thomas M. Coxsackic virus infection in acute myocardial infarction. Lancet 1977;i:883-4.

6 Griffiths PD, Hannington G, Booth JC. Coxsackie B virus infection and myocardial infarction. Results from a prospective epidemiologically controlled study, Lancet 1980;i:1387-9.

7 Saikku P, Leinonen M. Mattila K, et al. Serological evidence of an asseciation of a novel chlamydia, TWAR, with chronic coronary heart disease and acute mrocardial infarction. Lancet 1988;ii:983-6.

8 Syriänen J, Valtonen $V V$, Iivanainen $M$, Kaste $M$, Huttunen JK. Preceding infection as a major risk factor for ischaemic brain infarction in young and middle aged patients. Br Med $\mathcal{O}$ 1988;296:1156-60.

9 Röschlau P, Bernt E, Gruber W. Enzymatische bestimmung des Gesamts Cholesterins in Serum. I Clin Chem Clin Biochem 1974;12:103-7.

10 Lipid Research Clinics Program. Manual of lahoratory operations. Vol 1. Lipid and lipoprotein analvsis. Washington, DC: United States Government Printing Office, 1974. (DHEW (NIH) 75-628.)

11 Heding 1 ( $\mathrm{r}$. Radioimmunological determination of human $\mathrm{C}$ peptide in serum. Diabe:ologia 1975;11:5+1-8.

12 Dixon WJ, Brown MB, Engelman L, et al, eds. Biomedical data processing programs. Statistical software 1985. Los Angeles: University of California Programs. Sians

13 Siltanen P. Psvchosomatic factors in coronary heart disease. Ann Clin Re's $1984 ; 16: 1+2-55$

14 Hausen H, Milen A, Heinonen OP, Paunio 1. Caries in primary dentition and social class in high and low fluoride areas. Community Dent Oral Epidemiol 1982:10:33-6.

15 Preber $\mathrm{H}$, Bergström J. Cigarrette smoking in patients referred for periodontal treatment. F Dent Res 1986;94:102-8

6 Cianciola LJ, Park BH, Bruck E, Mosorich L, Cengo RJ. Prevalence of periodontal disease in insulin dependent diabetes mellitus (juvenile diabetes). F Am Dent Assoc 1982;104:653-60.

17 Carcia-Webb P, Bonser AM, Whiting D, Masarei JR. Insulin resistance-a risk factor for coronary heart disease? Scand F Clin Lab Invest 1983;43: $677-85$.

18 Shaw JH. Causes and control of dental caries. $N$ Engl f Med 1987:317: 996-1004.

19 Yudkin J. Dietary factors in atherosclerosis: sucrose. Lipids 1978;13:370-2.

20 Tunstall-Pedoe H, Rose G. Atherosclerosis as related to diet. In: Neuberger A, Jukas TH, eds. Biochemistry of nutrition. I. Baltimore: International Reviews of Biochemistry, 1979:245-79. (No 27.)

21 Royal College of Physicians of London. Committer on Fluoridation of Water Supplies. Fluoride, teeth and health: summary of a report on fluoride and its effects on teeth and health. London: Pitman Medical, 1976.

22 Chiemchaisri Y, Philips PH. Effect of dietary fluoride upon the magnesium calcinosis syndrome. F Nutr 1963;81:307-11.

23 Virtamo J, Huttunen JK. Minerals, trace elements and cardiovascular disease. An overview. Ann Clin Res 1988;20:102-13.

4 Reidy MA, Schwartz SM. Endothelial injury and regeneration. Part 4. Endotoxin: a non-denuding injury to aortic endothelium. Lab Invest 1983;48:25-34

25 Morel DW, Dicorleto PE, Chisholm GM. Modulation of endotoxin (LPS induced) endothelial cell toxicity by low density lipoprotein (LDL). American Heart Association Monograph 1985. No l+4.

26 Kerttula Y, Weber TH. Serum lipids in viral and bacterial meningitis. Scund $\mathcal{f}$ Infect Dis 1986;18:211-5.

27 Rasi V, Ikkala E, Valtonen V. Plasma betathromboglobulin in severe infection. Thromb Res 1982;26:267-74.

28 Osterud B, Bjorklid $\mathrm{E}$. The production and availability of tissue thromboplastin in cellular populations of whole blood exposed to various concentrations of endotoxin. Scandinavian fournal of Haematologv 1982;29:175-84.

29 Semerano N, Lattanzio A. Interaction of platelets with bacterial endotoxins. Agents Actions 1983;13:461-9.

30 Stuart MJ. Effect of endotoxin on arachiodonic acid release and thromboxane B2 production by human platelets. Am $\mathcal{F}$ Hematol 1981;11:159-64.

31 Tofter GH, Brezinski D, Schafer AI, et al. Concurrent morning increase in platelet aggregability and the risk of myccardial infarction and cardiac death. N Engl f.Med 1987;316:1514-8.

32 Muller JE, Stone PH, Turi ZG, et al. Circadian variation in the frequency of onset of acute myocardial infarction. $N$ Eingl f Med 1985:313:1315-22.

33 Genco RJ, Slots J. Host responses in periodontal discases. 7 Dent Res 1984;63:441-51.

(Accepted 19 Januan' 1989) 